\title{
Assessing the Effects of Uncoated and Coated Electrode on Response Variables in Electrical Discharge Machining for Ti-6Al-4V Titanium Alloy
}

\author{
S. Shirguppikara, M.S. Patil ${ }^{b}$, N.H. Phanc,*, T. Muthuramalingam ${ }^{\text {d, P.V. Dongc, N.C. Tam }}{ }^{c}$, B.T. Taic, \\ N.D. Minh', N.V. Duc \\ aDepartment of Mechanical Engineering Department, KLS GIT, Belagavi affiliated to VTU, Belagavi\&Department of \\ Mechanical Engineering Department, RIT, Rajaramnagar affiliated to SUK, Maharashtra, India, \\ ${ }^{b}$ Department of Mechanical Engineering Department, KLS GIT, Belagavi, Karnataka, India, \\ 'Hanoi University of Industry, No. 298, Cau Dien Street, Bac Tu Liem District, Hanoi, Vietnam, \\ ${ }^{d}$ Department of Mechatronics Engineering, SRM Institute of Science and Technology, SRM Nagar, Kattankulathur - \\ 603203, Kanchipuram, Chennai, TN, India.
}

Keywords:

Titanium alloy

EDM

$M R R$

TWR

Coated electrode

\section{* Corresponding author: \\ Nguyen Huu Phan \\ E-mail: nguyenhuuphan@haui.edu.vn}

Received: 8 December 2020

Revised: 30 January 2021

Accepted: 22 March 2021

\begin{abstract}
A B S T R A C T
The coated electrodes with high heat resistant alloy materials can considerably improve the efficiency of electrical discharge machining (EDM) process. In the present study, the influence of Aluminum Chromium Nickel Coated aluminium electrode was investigated on the quality criteria using EDM while machining Titanium alloy (Ti-6Al-4V). The peak current, gap voltage and pulse-on time were used as input parameters to analyze the material removal rate, tool wear rate and surface roughness under the L16 based Taguchi method and ANOVA method. It was observed that Aluminum Chromium Nickel (AlCrNi) coated electrode could produce higher material removal rate (MRR), lower of tool wear rate (TWR) and surface roughness ( $R a$ ) than uncoated electrode. Compared with EDM with uncoated electrodes, the quality indicators in EDM with coated electrode are better, namely 8\% higher MRR, the lower TWR and Ra are 8\% and 24\%, respectively. The better surface finish was also observed with the coated electrode due to its thermal conductivity.
\end{abstract}

(C) 2021 Published by Faculty of Engineering

\section{INTRODUCTION}

Electric discharge machining (EDM) is the thermal erosion method in which the material can be removed by melting or vaporizing the materials from the surface of workpiece. The controlled erosion of the workpiece can be happened by applying repetitive electrical sparks between the work and tool electrode submerged in a dielectric medium [1]. This machining process is extensively employed in the production of complex shape dies and molds tools with higher strength materials such as tungsten carbide, hard alloy steels, hastalloy, nimonic, etc [2]. The better finishing of the components for aeronautical and automobile industries can be machined using EDM method [3]. 
It was experimentally investigated to analyze the effects of nickel-coated composite electrode and diamond-nickel-coated composite electrode for reducing the side tool wear of the specimens [4]. A process simulation was presented to analyze the residual stress in micro-EDM machining on molybdenum. The pulse duration can highly contributed on the crater dimension and the tool wear percentage [5]. The impact of grain size of the boron-doped CVD diamond coating was investigated on wear behavior in micro EDM process. The CVD diamond coatings could produce tiny discharge craters compared to microcrystalline diamond coatings with melting crystalline phase around the discharge crater [6]. The CNT coated electrodes can improve the higher material removal rate (MRR) and lower tool wear rate (TWR). The surface of the electrode is coated with diamond material by the PCD method in EDM for machining SKD11 and tungsten carbide (G5), and this causes a very sharp decrease in TWR [7]. Compared with uncoated electrodes, the wear of the coated electrode is reduced approximately 2050 times. EDM using diamond-coated electrodes has resulted in increased electrode wear resistance, this results in a significantly improved machining productivity $[8,9]$. Survey results of the effects of TiN and TiAlN coating on $\mathrm{Cu}$ electrode's wear resistance in EDM showed that TWR of TiN and TiAlN coated $\mathrm{Cu}$ electrode has been strongly improved [10]. And compared with the TiAlN coated electrode, the TWR of TiN coated electrode is significantly smaller. TWR in EDM using zinc, silver and hard chrome coated copper electrode is higher than it of uncoated electrode, this is due to the coating material being removed from the substrate electrode's surface layer [11]. The reason is that the thickness of the coating $(\approx 3 \mu \mathrm{m})$ is too small. The surface roughness ( $\mathrm{Ra}$ ) was also reduced as compared with uncoated tools [12]. The TiC-Cu powder tool electrode was prepared with composite coating on AISI 1020 steel by the electrodischarge coating (EDC) process. The experimental results revealed that the peak current, processing range, and pulse on time had a major effect on the performance of the coating due to alteration in the deposition of the coating material [13]. A novel TiN$\mathrm{Cu}$ electrical discharge machining electrode was proposed and fabricated by gel injection molding with the mixture of TiN-Cu powders, sodiumalginate dispersant and gelatin binder. The influence of the gel properties was investigated on surface microstructures and relative loss-rate of the newly developed EDM electrode to optimize the fabrication conditions [14]. It was found that tool wear was increased with higher voltage and current values [15]. The effect of the titanium carbide (TiC) in sintered copper-tungsten $(\mathrm{Cu}-\mathrm{W})$ electrodes on their EDM performance was investigated. The highest relative density and lowest electrical resistivity could be obtained by $15 \% \mathrm{TiC}$ addition and thus produced lowest TWR, highest MRR and best surface finish [16]. The copper coated aluminum (Al) electrodes could significantly affects the MRR, TWR and Ra in EDM process [17]. The CNT coated electrode and TiN coated electrodes can also increase the efficiency of the EDM process compared to uncoated electrodes [18-20]. The study portrayed the potential of the EDM input parameters for improving the MRR and surface quality of Co-Cr alloy and DSS alloy [21]. Power mixed EDM and its influence on machining performance were studied for various workpiece materials [22-25].

From the detailed experimental investigations, it was inferred that only little attention was provided on analyzing the effects of coated electrodes in EDM process. Specific methodologies like power mixed EDM, dry EDM, ultrasonic EDM etc were used in EDM but thin film coated electrode tools were used in very few experimental work. Aluminum-Chromium-Nickel (AlCrNi) is a very promising coating material for the electrodes in EDM, but no studies have been investigated with this coating material. In addition, aluminum electrodes are also very popularly used in EDM, however the number of studies done with coating aluminum electrode in EDM is very little, and in particular, no studies have been done with the $\mathrm{AlCrNi}$ Coated $\mathrm{Al}$ electrode in EDM. Hence the present investigation was carried out. In the present study, the influence of Aluminium-ChromiumNickel (AlCrNi) Coated $\mathrm{Al}$ electrode was investigated on the quality criteria using EDM while machining Titanium alloy (Ti - 6Al-4V).

\section{EXPERIMENTAL METHODOLOGY}

\subsection{Selection of workpiece}

The titanium alloy (Ti-6Al-4V) was used as workpiece specimens in the present study, since it is mostly utilized in manufacturing industries owing to its higher stregnth, corrosion resistance, lower density better weldability, workability and 
thermal process ability. The materials were procured from Bharat Aerospace, Mumbai with chemical composition as shown in Table 1. The physical properties of the specimens is given in Table 2.

Table 1. Chemical composition of Ti-6Al-4V.

\begin{tabular}{|c|c|c|c|c|c|}
\hline Element & $\mathbf{A l}$ & $\mathbf{V}$ & $\mathbf{C}$ & $\mathbf{F e}$ & $\mathbf{T i}$ \\
\hline $\mathrm{Wt}(\%)$ & 5.60 & 4.50 & 0.02 & 0.012 & Balance \\
\hline
\end{tabular}

Table 2. Physical properties of Ti-6Al-4V.

\begin{tabular}{|l|l|}
\hline Property & Value \\
\hline Melting point $\left({ }^{\circ} \mathrm{C}\right)$ & 1.649 \\
\hline Density $(\mathrm{g} / \mathrm{cm} 3)$ & 4.43 \\
\hline Thermal conductivity $(\mathrm{W} / \mathrm{m}-\mathrm{K})$ & 7.2 \\
\hline Hardness (HRA) & $48-49$ \\
\hline Electrical resistivity $(\mathrm{ohm}-\mathrm{cm})$ & 170 \\
\hline
\end{tabular}

\subsection{Selection of tool electrodes}

The machining experiments were performed in electric discharge machining process using uncoated Al tool electrode and $\mathrm{AlCrNi}$ coated tool electrodes. The main aim of experiment is to study the effects of AlCrNi coated tool electrode on machining performances as comparison with uncoated electrodes. The machining experiments have been performed with conventional $\mathrm{Al}$ tool electrode and uniformly $\mathrm{AlCrNi}$ coated $\mathrm{Al}$ electrode with the diameter of $9.95 \mathrm{~mm}$. Coating thickness of TiN was measured by surface rugosity meter avaible at Oerlikon Balzers Coating India Pvt. Ltd., Pune. Average diameter of thin film coated TiN micro tool electrode is 500.00 micron. Schematic of tool electrode is shown on Figure 1.

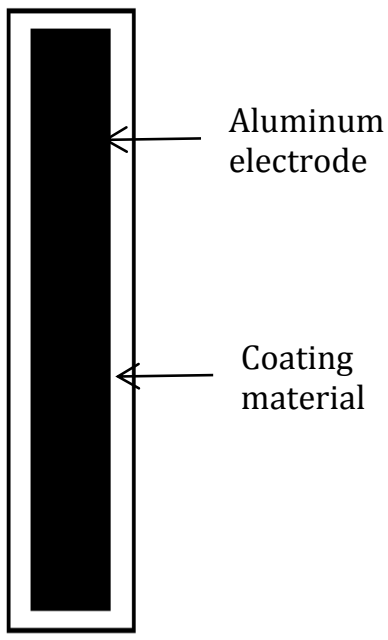

Fig. 1. Schematic diagram of coated tool.
The development of thin film coating of AlCrNi was achieved using physical vapour deposition method (PVD). This uniform coating on tool electrode was conducted in Balzer India Pvt. Ltd, Pune, India. The presence of $\mathrm{Al}$ and chromium ( $\mathrm{Cr}$ ) in the coating was characterized by the proposed method.

\subsection{Selection of process parameters and variables}

The machining experiments have been performed with conventional Aluminum tool electrode and uniformly AlCrNi coated aluminum electrode with the diameter of $10 \mathrm{~mm}$. The experimental investigation was performed to produce higher MRR with lower TWR and surface roughness for improving machining efficiency. The coating enhances the electrical conductivity and better abrasive wear with the compatible dielectric medium. Experimental work were performed on ZNC EDM (Make : Electronica India, Pvt. Ltd, India. Photograph of ZNC EDM is shown in Figure 2.

\subsection{Design experimental and ANOVA}

Mechanism of EDM processing is unclear due to the large number of technology parameters. Experimental design using Taguchi method is very simple; it is used in many technical fields with high efficiency. The process parameters in the experimental matrix may choose large numbers $(3$ $\div 50$ ) with the different possible values. The value of the levels of the research technology parameters is any selected. Especially, studies with new machining methods and unclear mechanism will be very suitable with Taguchi method [33]. The design of an experimental matrix using the Taguchi method through special orthogonal matrices is available. With this method, the number of process parameters included in the empirical matrix and their levels are maximized, but the number of experiments is minimized. The process parameters studied can be qualitative or quantitative, discrete nature of the input variables, interactions between input parameters, etc. These problems cannot be realized in traditional experimental design methods. Compared with the experiments via traditional method, the testing cost of Taguchi method is reduced by $88.9 \%$, and the results of the two methods are the same [34]. In some specific cases, Taguchi method can be used as a substitute for central composite design, Shainin System DoE, Response Surface Methodology (RSM), Full Factorial Design, etc [35-37]. Taguchi technique is 
normally used in linear interactions only. This is due to the fact that in Taguchi design, interactions between controls factors are aliased with their main effects. Selection of an orthogonal array depends upon the number of factors, and their degrees of freedom (dof) from each factor. The change in the mean of quality characteristics is used to determine the influence of parameters on the research process. Therefore, Taguchi's method can be used to study the technological parameters of EDM process.

For this study the main effects of the input parameters were considered as shown in Table 3. The selection of an orthogonal array depends upon the number of factors and degrees of freedom with each factor. For this study 3 main factors were considered, with 3 main factors had four levels, each having three DOFs, thus, the total sum of DOFs was 9, Table 3. Therefore, $\mathrm{L}_{16}$ based $\mathrm{OA}$ was chosen for the final experimental investigation.

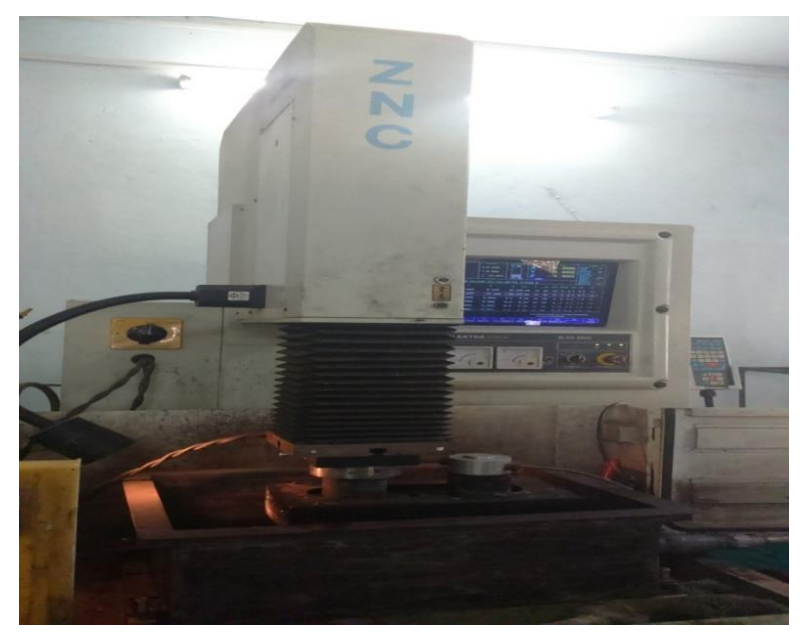

Fig. 2. Experimental setup (ZNC EDM).

Table 3. Process parameters and levels.

\begin{tabular}{|c|c|c|c|c|c|c|}
\hline \multirow{2}{*}{ Parameters } & \multirow{2}{*}{ Symbol } & \multicolumn{3}{|c|}{ Levels } & DOF \\
\cline { 3 - 7 } & & 1 & 2 & 3 & 4 & \\
\hline Peak Current & $\mathrm{I}$ & 10 & 20 & 30 & 40 & 3 \\
\hline Gap Voltage & Vg & 40 & 45 & 50 & 55 & 3 \\
\hline Pulse-ON Time & TON & 100 & 500 & 1000 & 1500 & 3 \\
\hline \multicolumn{2}{|l|}{ Total } \\
\hline
\end{tabular}

\subsection{Computation of response parameters}

Material removal rate, tool wear rate and surface roughness were considered as performance measures to access the quality in the present study. Material removal rate (MRR) was computed using Eqn 1.

$$
\operatorname{MRR}(\mathrm{gm} / \mathrm{min})=\frac{W i-W f}{t}
$$

Where, Wf and Wi were final weight and initial weight of workpiece before machining and after machining respectively and $t$ is machining time.

Tool wear rate (TWR) was computed using Eqn 2.

$$
\operatorname{TWR}(\mathrm{gm} / \mathrm{min})=\frac{T i-T f}{t}
$$

Where, Ti and Tf are initial weight of tool before machining and final weight of tool electrode and $\mathrm{t}$ is machining time.

Surface roughness $(\mathrm{Ra})$ of machined workpiece surface was measured by contact type surface roughness tester (Taylor Hobson machine, Surtronic S-100 Series Surface Roughness Tester) with the cutoff length of $0.8 \mathrm{~mm}$. Assessment were performed on surface of workpiece machine (four directions; outside to inside). Each surface was assessed four times and then noted average value of surface roughness. Prob tip radius was 5 micro meter and sampling length was $2.5 \mathrm{~mm}$.

\section{RESULTS AND DISCUSSION}

In the present study, an attempt has been performed to investigate the effect of coated and uncoated electrodes on the material removal rate (MRR), tool wear rate (TWR) and surface roughness $(\mathrm{Ra})$ on machining titanium (Ti-6Al-4V) alloy. The experimental results have been computed and recorded as shown in Table 4.

\subsection{Effects on tool coating on material removal rate}

Table 5 shows the analysis of variance(ANOVA) for material removal rate with uncoated electrode. It was observed that Current (I) has the major significance on material removal rate due to its importance on determining spark energy in EDM process. It can be stated that the pulse-on time (TON) has also considerable effect, since it could affect duration of spark energy to be delivered. 
Figure 3 shows the main effects plots on MRR with uncoated electrodes which has been obtained using Minitab software package. It shows the behavior of process parameters on MRR in EDM process. It is pictorial representation of the ANOVA analysis. It can be seen that the material removal rate increases with increasing with higher pulse time. The deeper discharge craters have been formed under higher pulse time and resulted in higher MRR along with each spark, since the spark energy is directly proportional to the pulse-on time.

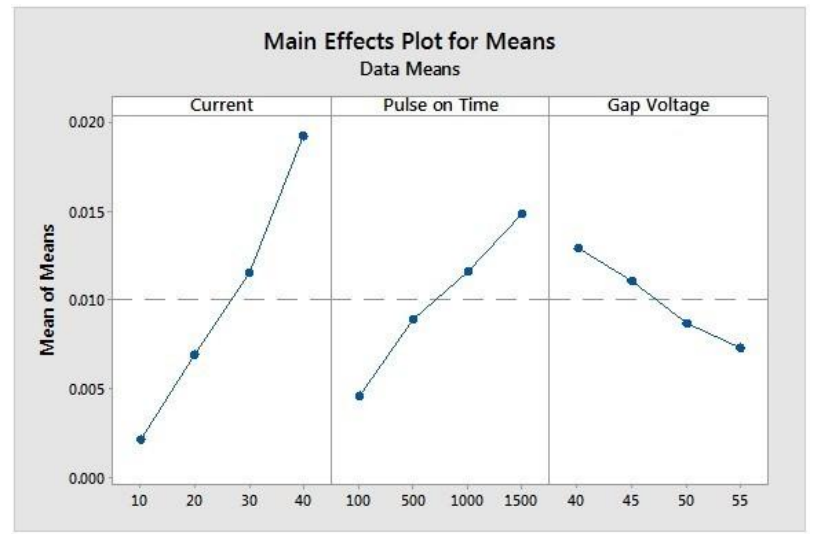

Fig. 3. Main effect plot on MRR using Al electrode.

Table 6 shows the analysis of variance(ANOVA) for material removal rate with coated electrode. The coated electrodes could also produce same effect as that of uncoated tool electrode in EDM process. However after at $500 \mu \mathrm{s}$, the MRR was also reduced owing to the current required to charge the machining zone. This phenomenon was been observed by few research works[25, 26, 27]. Since the gap voltage has not much contributed during the discharge process, it has very lower influence on producing craters and resulted in less effect on MRR [28,29].

Figure 4 shows the main effects plots on MRR with coated electrodes which has been obtained using Minitab software package. It was observed that peak current has the ability to produce the larger discharge craters and possess higher influence on determining MRR.

While analyzing the consolidated results, if was observed that AlCrNi coated electrodes could improve the $8 \%$ higher MRR as compared with uncoated electrode owing to the higher electrical and thermal conductivity of the tool electrode surface of the surface coatings during the machining process as shown in Figure 5.

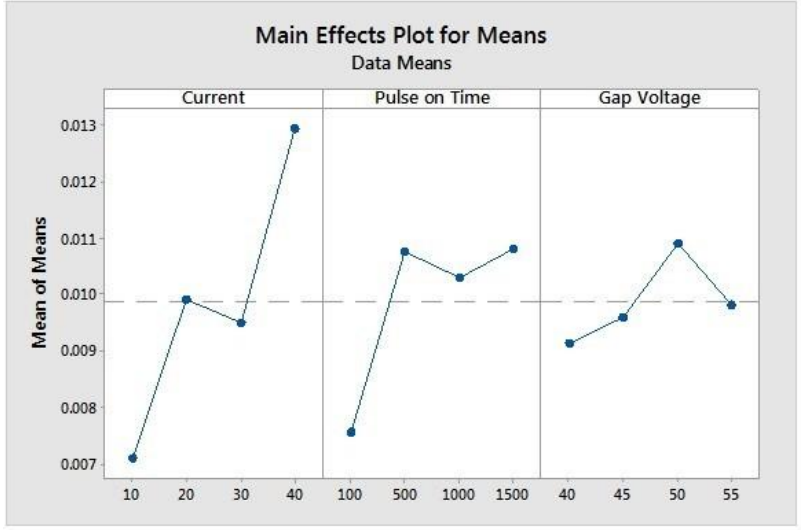

Fig. 4. Main effect plot for MRR using AlCrNi coated electrode.

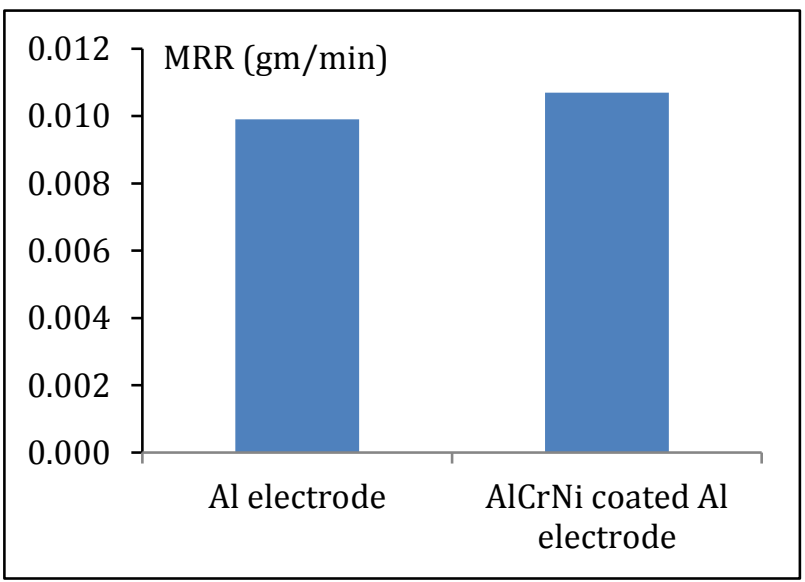

Fig. 5. Comparison of MRR with uncoated and coated electrode.

\subsection{Effects on tool coating on Tool wear Rate}

Table 7 shows the analysis of variance (ANOVA) for tool wear rate with uncoated electrode. It was observed that Current (I) has the major significance on tool removal rate due to its importance on determining spark energy in EDM process. It can be stated that the pulseon time $\left(\mathrm{T}_{O N}\right)$ has also considerable effect, since it could affect duration of spark energy to be delivered $[27,28]$.

Fig. 6 shows the main effects plots on TWR with uncoated electrodes which has been obtained using Minitab software package. It shows the behavior of process parameters on TWR in EDM process. It can be seen that the tool wear rate increases with increasing with higher pulse time. The deeper discharge craters have been formed under higher pulse time and resulted in higher TWR along with each spark, since the spark energy is directly proportional to the pulse-on time. 


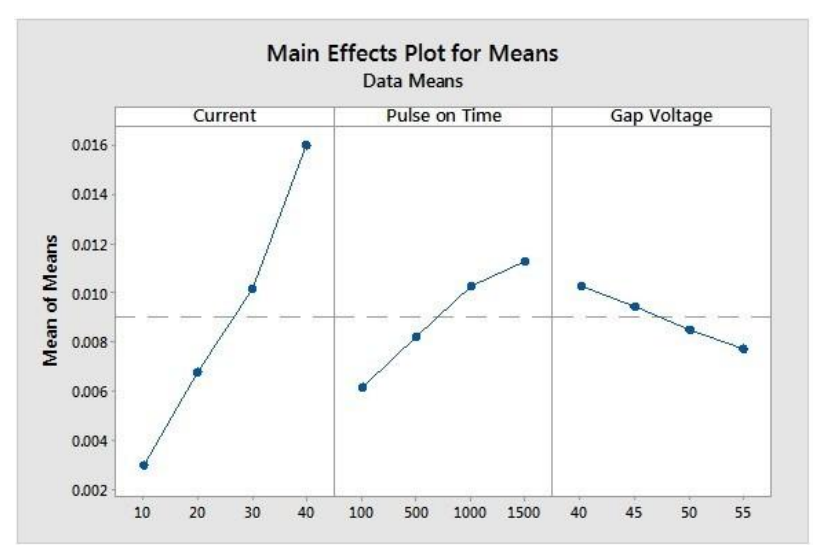

Fig. 6. Main effect plot for TWR using Al electrode.

Table 8 shows the analysis of variance(ANOVA) for tool wear rate with coated electrode. The coated electrodes could also produce same effect as that of uncoated tool electrode in EDM process. However the coating could reduce the effects of creating craters over the tool electrode. Hence it could produce lower tool wear rate compared with uncoated electrode. Fig. 7 shows the main effects plots on TWR with coated electrodes which has been obtained using Minitab software package. It was observed that peak current has the ability to produce the larger discharge craters and possess higher influence on determining TWR.

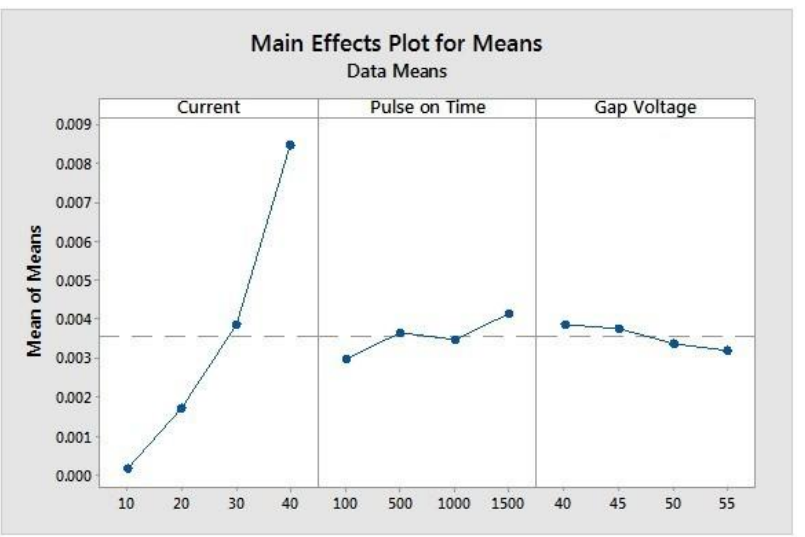

Fig. 7. Main effect plot for TWR using AlCrNi coated electrode.

While analyzing the consolidated results, if was observed that AlCrNi coated electrodes could improve the $24 \%$ lower TWR as compared with uncoated electrode owing to the less erosion made by surface coatings during the machining process as shown in Figure 8. Since the $\mathrm{AlCrNi}$ is hard coating which has been used to protect tools from wear during machining processes, less reduction in tool wear was observed as compared to uncoated $\mathrm{Al}$ electrode.

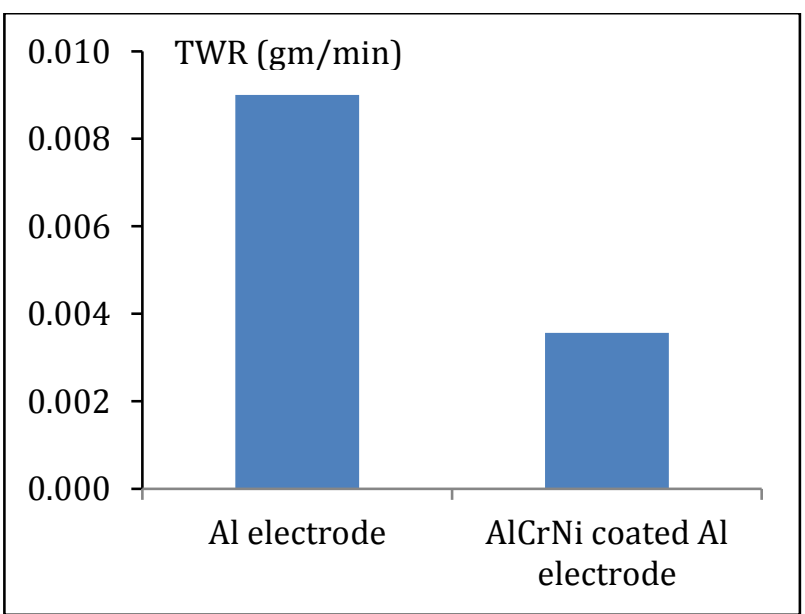

Fig. 8. Comparison of TWR with uncoated and coated electrode

\subsection{Effects on tool coating on surface roughness}

Table 9 shows the analysis of variance (ANOVA) for surface roughness with uncoated electrode. The surface roughness is generally characterized by the size and the distribution of the craters in EDM process. It was observed that current (I) has the major significance on surface roughness due to its importance on determining crater formation in EDM process $[29,30]$. It can be stated that the pulseon time $\left(\mathrm{T}_{O N}\right)$ has also considerable effect, since it could affect duration of spark energy.

Figure 9 shows the main effects plots on Ra with uncoated electrodes which have been obtained using Minitab software package. It shows the behavior of process parameters on Ra in EDM process. It can be seen that the surface roughness increases with crater size. The deeper and larger discharge craters have been formed under higher pulse time and resulted in higher Ra along with each spark, since the spark energy is directly proportional to the pulse-on time.

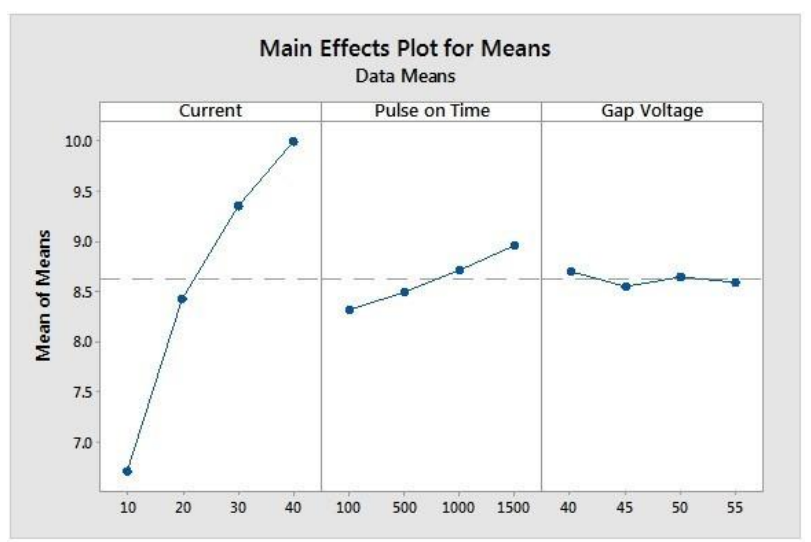

Fig. 9. Main effect plot for Ra using Al electrode. 
Table 10 shows the analysis of variance (ANOVA) for surface roughness with coated electrode. The coated electrodes could also produce same effect as that of uncoated tool electrode in EDM process. However the coating could reduce the effects of creating craters over the tool electrode. Hence it could produce lower surface roughness compared with uncoated electrode. Figure 10 shows the main effects plots on Ra with coated electrodes which has been obtained using Minitab software package. It was observed that peak current has the ability to affect the size of the discharge craters and possess higher influence on determining Ra.

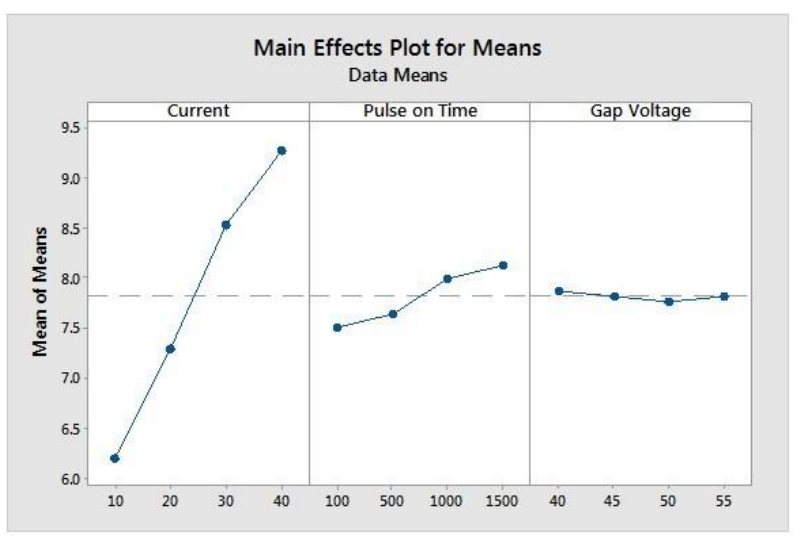

Fig. 10. Main effect plot for Ra using AlCrNi coated electrode.

While analyzing the consolidated results, if was observed that AlCrNi coated electrodes could improve the $10 \%$ lower $\mathrm{Ra}$ as compared with uncoated electrode owing to the less erosion made by surface coatings during the machining process as shown in Figure 11. Since the $\mathrm{AlCrNi}$ is hard coating which has been used to distribute the craters as uniform during machining processes, less surface roughness was observed as compared to uncoated $\mathrm{Al}$ electrode.

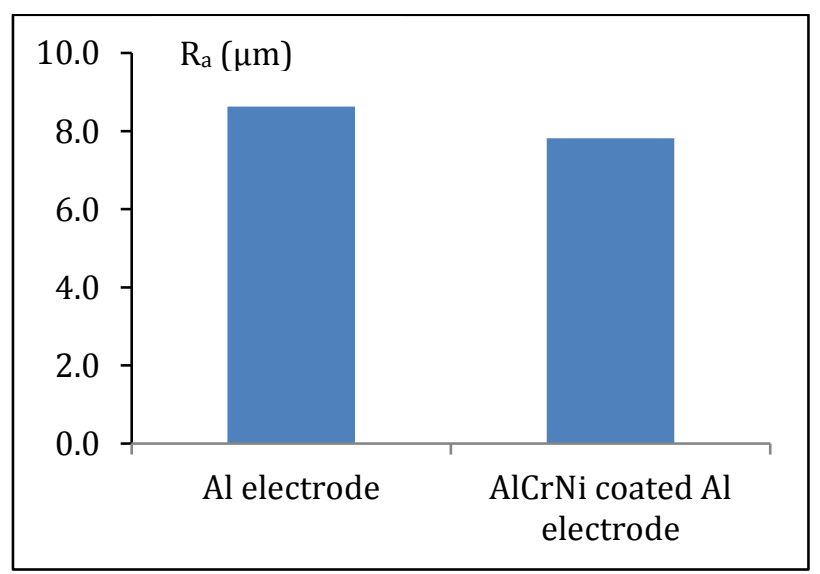

Fig. 11. Comparison of $R_{a}$ values with uncoated and coated electrode.
Figure 12 shows the surface morphology analysis of machined surface using scanning electron microscopic (SEM). The JEOL JSM-6360, Mira-3 Tescan, Brno-Czech Republic, Field emission scanning electron microscope (FE-SEM) is available at Physics Department, Shivaji University, Kolhapur. SEM conducted at $1000 \mathrm{X}$ and observed surface topography of both surfaces; aluminum electrode tool and $\mathrm{AlCrNi}$ coated electrode. It was observed that a significant amount of micro cracks over the machined surface of titanium alloy due to residual stress formation [31-32]. AlCrNi coated electrode could produce only very few micro cracks due to the thermal and electrical conductivity of the coating in EDM process. It could make very less residual stress formation over the top layer of the machined surface than uncoated tool electrode. It was concluded that $\mathrm{AlCrNi}$ coated tool electrode improves topography of machined surface as compared to Al electrode.

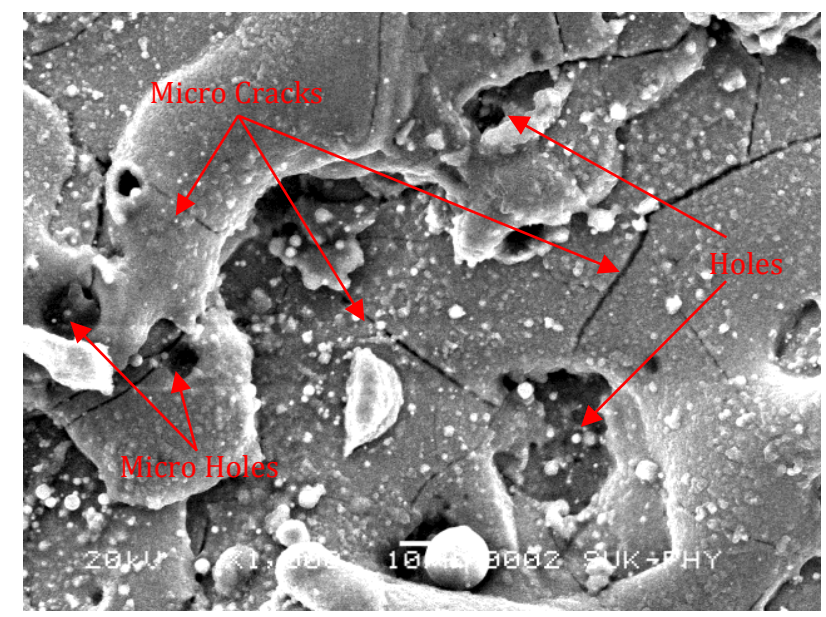

a) Machined surface with uncoated electrode

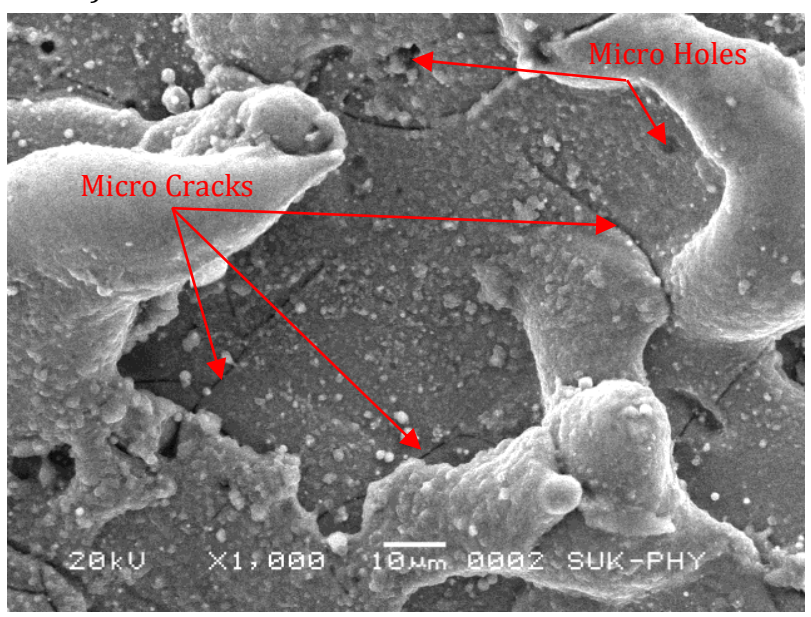

b) Machined surface with AlCrNi coated electrode

Fig. 12. SEM images of machining surfaces. 
Table 4. Experimental results with uncoated $\mathrm{Al}$ electrode and $\mathrm{AlCrNi}$ coated electrode.

\begin{tabular}{|c|c|c|c|c|c|c|c|c|c|}
\hline \multirow{2}{*}{$\begin{array}{l}\text { Expt. } \\
\text { No. }\end{array}$} & \multirow{2}{*}{$\begin{array}{c}\text { Current } \\
\text { (I) }\end{array}$} & \multirow{2}{*}{$\begin{array}{c}\begin{array}{c}\text { Gap } \\
\text { Voltage }\end{array} \\
\left(V_{g}\right)\end{array}$} & \multirow{2}{*}{$\begin{array}{c}\begin{array}{c}\text { Pulse- } \\
\text { ON } \\
\text { Time }\end{array} \\
\text { (Ton ) }\end{array}$} & \multicolumn{3}{|c|}{ Uncoated Al electrode } & \multicolumn{3}{|c|}{ AlCrNi coated Al electrode } \\
\hline & & & & $\begin{array}{c}\text { MRR } \\
\text { (gm/min) }\end{array}$ & $\begin{array}{c}\text { TWR } \\
\text { (gm/min) }\end{array}$ & $\begin{array}{c}\mathrm{R}_{\mathrm{a}} \\
(\mu \mathrm{m})\end{array}$ & $\begin{array}{c}\text { MRR } \\
\text { (gm/min) }\end{array}$ & $\begin{array}{c}\text { TWR } \\
\text { (gm/min) }\end{array}$ & $\begin{array}{c}\mathrm{R}_{\mathrm{a}} \\
(\mu \mathrm{m})\end{array}$ \\
\hline 1 & 10 & 40 & 100 & 0.002 & 0.0023 & 6.664 & 0.004 & 0.0001 & 6.111 \\
\hline 2 & 10 & 45 & 500 & 0.0022 & 0.0028 & 6.683 & 0.0093 & 0.0002 & 6.162 \\
\hline 3 & 10 & 50 & 1000 & 0.0019 & 0.0041 & 6.691 & 0.0086 & 0.0002 & 6.251 \\
\hline 4 & 10 & 55 & 1500 & 0.0027 & 0.0029 & 6.815 & 0.0065 & 0.0003 & 6.294 \\
\hline 5 & 20 & 45 & 100 & 0.0019 & 0.005 & 7.781 & 0.0053 & 0.0014 & 6.874 \\
\hline 6 & 20 & 40 & 500 & 0.0073 & 0.0058 & 8.325 & 0.0107 & 0.0022 & 6.976 \\
\hline 7 & 20 & 55 & 1000 & 0.0075 & 0.0076 & 8.662 & 0.0089 & 0.0011 & 7.648 \\
\hline 8 & 20 & 50 & 1500 & 0.0111 & 0.0087 & 8.981 & 0.0148 & 0.0022 & 7.669 \\
\hline 9 & 30 & 50 & 100 & 0.0053 & 0.0068 & 9.116 & 0.0077 & 0.0031 & 8.045 \\
\hline 10 & 30 & 55 & 500 & 0.0097 & 0.0098 & 9.203 & 0.0106 & 0.0041 & 8.338 \\
\hline 11 & 30 & 40 & 1000 & 0.0141 & 0.0118 & 9.412 & 0.0098 & 0.0037 & 8.768 \\
\hline 12 & 30 & 45 & 1500 & 0.0172 & 0.0124 & 9.665 & 0.0099 & 0.0046 & 8.946 \\
\hline 13 & 40 & 55 & 100 & 0.0093 & 0.0106 & 9.706 & 0.0133 & 0.0074 & 9.013 \\
\hline 14 & 40 & 50 & 500 & 0.0164 & 0.0145 & 9.783 & 0.0125 & 0.0081 & 9.112 \\
\hline 15 & 40 & 45 & 1000 & 0.0229 & 0.0177 & 10.112 & 0.0139 & 0.0089 & 9.313 \\
\hline 16 & 10 & 40 & 100 & 0.0282 & 0.0212 & 10.391 & 0.0121 & 0.0095 & 9.623 \\
\hline
\end{tabular}

Table 5. ANOVA of MRR using Al electrode.

\begin{tabular}{|c|c|c|c|c|c|c|}
\hline Source & DF & SS & MS & F-Value & P-Value & Contribution \% \\
\hline $\mathrm{I}$ & 3 & 0.000629 & 0.00021 & 45.01 & 0 & 65.93 \\
\hline $\mathrm{T} O N$ & 3 & 0.000223 & 0.000074 & 15.94 & 0.003 & 23.37 \\
\hline $\mathrm{V}_{g}$ & 3 & 0.000074 & 0.000025 & 5.31 & 0.4 & 2.75 \\
\hline Error & 6 & 0.000028 & 0.000005 & - & - & - \\
\hline Total & 15 & 0.000954 & \multicolumn{5}{|c|}{} \\
\hline \multicolumn{7}{|c|}{$\mathrm{S}=0.0021585 ; \mathrm{R}-\mathrm{Sq}=97.07 \% ; \mathrm{R}-\mathrm{Sq}(\mathrm{adj})=92.67 \%$} \\
\hline
\end{tabular}

Table 6. ANOVA of MRR using AlCrNi coated electrode.

\begin{tabular}{|c|c|c|c|c|c|c|}
\hline Source & DF & SS & MS & F-Value & P-Value & Contribution \% \\
\hline $\mathrm{I}$ & 3 & 0.000069 & 0.000023 & 3.94 & 0.072 & 60.59 \\
\hline $\mathrm{T}_{O N}$ & 3 & 0.000029 & 0.00001 & 1.63 & 0.278 & 31.91 \\
\hline $\mathrm{V}_{g}$ & 3 & 0.000007 & 0.000002 & 0.38 & 0.774 & 2.5 \\
\hline Error & 6 & 0.000035 & 0.000006 & - & - & - \\
\hline Total & 15 & 0.00014 & \multicolumn{7}{|l}{} \\
\hline \multicolumn{7}{|c|}{$\mathrm{S}=0.0024210 ; \mathrm{R}-\mathrm{Sq}=74.83 \% ; \mathrm{R}-\mathrm{Sq}(\mathrm{adj})=37.07 \%$} \\
\hline
\end{tabular}

Table 7. ANOVA of TWR using Al electrode.

\begin{tabular}{|c|c|c|c|c|c|c|}
\hline Source & DF & SS & MS & F-Value & P-Value & Contribution \% \\
\hline I & 3 & 0.000364 & 0.000121 & 53.43 & 0 & 80 \\
\hline$T_{\mathrm{ON}}$ & 3 & 0.000062 & 0.000021 & 9.13 & 0.012 & 13.62 \\
\hline Vg & 3 & 0.000015 & 0.000005 & 2.17 & 0.192 & 3.29 \\
\hline Error & 6 & 0.000014 & 0.000002 & - & - & - \\
\hline Total & 15 & 0.000455 & \multicolumn{7}{|l|}{} \\
\hline \multicolumn{7}{|c|}{$\mathrm{S}=0.0015078 ; \mathrm{R}-\mathrm{Sq}=97.00 \% ; \mathrm{R}-\mathrm{Sq}(\mathrm{adj})=92.51 \%$} \\
\hline
\end{tabular}

Table 8. ANOVA of TWR using AlCrNi coated electrode.

\begin{tabular}{|c|c|c|c|c|c|c|}
\hline Source & DF & SS & MS & F-Value & P-Value & Contribution \% \\
\hline $\mathrm{I}$ & 3 & 0.000156 & 0.000052 & 360.41 & 0 & 97.5 \\
\hline $\mathrm{T} O N$ & 3 & 0.000003 & 0.000001 & 6.27 & 0.028 & 1.87 \\
\hline $\mathrm{V}_{g}$ & 3 & 0.000001 & 0 & 2.62 & 0.145 & 0.62 \\
\hline Error & 6 & 0.000001 & 0 & - & - & 0.62 \\
\hline Total & 15 & 0.00016 & \multicolumn{7}{|c|}{-} \\
\hline \multicolumn{7}{|l}{$\mathrm{S}=0.0003794 ; \mathrm{R}-\mathrm{Sq}=99.46 \% ; \mathrm{R}-\mathrm{Sq}(\mathrm{adj})=98.65 \%$} \\
\hline
\end{tabular}


Table 9. ANOVA of Ra using Al electrode

\begin{tabular}{|c|c|c|c|c|c|c|}
\hline Source & DF & SS & MS & F-Value & P-Value & Contribution \% \\
\hline $\mathrm{I}$ & 3 & 24.3974 & 8.13246 & 161.13 & 0 & 95 \\
\hline $\mathrm{T}_{\mathrm{ON}}$ & 3 & 0.9366 & 0.31219 & 6.19 & 0.029 & 0.64 \\
\hline $\mathrm{V}_{g}$ & 3 & 0.0426 & 0.0142 & 0.28 & 0.837 & 0.16 \\
\hline Error & 6 & 0.3028 & 0.05047 & - & - & - \\
\hline Total & 15 & 25.6794 & \multicolumn{7}{|c|}{} \\
\hline \multicolumn{7}{|c|}{$\mathrm{S}=0.224656 ; \mathrm{R}-\mathrm{Sq}=98.82 \% ; \mathrm{R}-\mathrm{Sq}(\mathrm{adj})=97.05 \%$} \\
\hline
\end{tabular}

Table 10. ANOVA of Ra using AlCrNi coated electrode.

\begin{tabular}{|c|c|c|c|c|c|c|}
\hline Source & DF & SS & MS & F-Value & P-Value & Contribution \% \\
\hline $\mathrm{I}$ & 3 & 21.8944 & 7.29813 & 177.69 & 0 & 94.46362 \\
\hline $\mathrm{T} O N$ & 3 & 1.0166 & 0.33887 & 8.25 & 0.015 & 4.38613144 \\
\hline $\mathrm{V}_{g}$ & 3 & 0.0202 & 0.00672 & 0.16 & 0.917 & 0.08715311 \\
\hline Error & 6 & 0.2464 & 0.04107 & - & - & 1.0630954 \\
\hline Total & 15 & 23.1776 & - & - \\
\hline \multicolumn{7}{|c|}{$\mathrm{S}=0.202663 ; \mathrm{R}-\mathrm{Sq}=98.94 \% ; \mathrm{R}-\mathrm{Sq}$ (adj) $=97.34 \%$} \\
\hline
\end{tabular}

\section{CONCLUSION}

In the present study, the influence of Aluminum Chromium Nickel Coated aluminium electrode was investigated on the quality criteria using EDM while machining Ti - 6Al-4V. From the experimental investigation and analysis, the following conclusions have been made.

- Aluminum Chromium Nickel coated electrode can produce $8 \%$ higher material removal rate with lower tool wear rate than uncoated electrode due to higher electrical conductivity and better surface hardness, respectively.

- The proposed coated tool electrode can produce $24 \%$ better surface finish than uncoated tool electrode due to ability of producing tiny and uniformly distributed craters over the machined surface.

- Since surface hardness is influenced by resolidification of tool electrode, the coated tool electrode can produce higher surface hardness owing to the higher melting point of coated tool electrode.

- The Optimization of the technological parameters in EDM with coated electrode can further enhance the quality indicators. It is very much needed to concentrate in this area further.

\section{REFERENCES}

[1] M. Kunieda, B. Lauwers, K.P. Rajurkar, B. Schumacher, Advancing edm through fundamental insight into the process, CIRP annals, vol. 54, iss. 2, pp. 64-87, 2005, doi: 10.1016/S0007-8506(07)60020-1
[2] N.M. Abbas, N. Yusoff, R. Mahmod, Electrical discharge machining (edm): practices in malaysian industries and possible change towards green manufacturing, Procedia Engineering, vol. 41, pp. 1684-1688, 2012, doi: 10.1016/j.proeng.2012.07.368

[3] K. Ho, S. Newman, State of the art electrical discharge machining (EDM), International Journal of Machine Tools and Manufacture, vol. 43 , iss. 13 , pp. 1287-1300, 2003, doi: 10.1016/S0890-6955(03)00162-7

[4] Y. Liu, W. Wang, W. Zhang, F. Ma, D. Yang, Z. Sha, S. Zhang, Experimental Study on Electrode Wear of Diamond-Nickel Coated Electrode in EDM Small Hole Machining, Advances in Materials Science and Engineering, vol. 2019, pp. 1-10, 2019, doi: $10.1155 / 2019 / 7181237$

[5] P. Allen, X. Chen, Process simulation of micro electro-discharge machining on molybdenum, Journal of Materials Processing Technology, vol. 186, iss. $1-3$, pp. 346-355, 2007, doi: 10.1016/j.jmatprotec.2007.01.009

[6] E. Uhlmann, S. Rosiwal, K. Bayerlein, M. Röhner, Influence of grain size on the wear behavior of CVD diamond coatings in micro-EDM, The International Journal of Advanced Manufacturing Technology, vol. 47, no. 9-12, pp. 919-922, 2010, doi: 10.1007/s00170-009-2131-7

[7] K. Suzuki, A. Sharma, S. Sano, M. Iwai, T. Uematsu, An new Application of PCD as a Very Low Wear electrode Material for EDM, Key Engineering Materials, vol. 291 - 292, pp. 549 -554, 2005, doi: 10.4028/www.scientific.net/KEM.291-292.549

[8] E. Uhlmann, M. Langmack, R. Garn, D. Oberschmidt, J. Fecher, S.M. Rosiwal, R.F. Singer, Using diamond coated tool-electrodes for drilling 
micro holes with EDM, in 11th International Conference of the European Society for Precision Engineering and Nanotechnology, 23-26 May, 2011, Como, Italy, pp.492-496

[9] E. Uhlmann, S. Piltz, M. Roehner, Influence of diamond Coatings on Electrode Wear in Micro $E D M$, in 7th International Conference of the European Society for Precision Engineering and Nanotechnology (EUSPEN), 20-24 May, 2007, Bremen, Germany, pp 525-528.

[10] D.L. Panchal, S.K. Biradar, V.Y. Gosavi, Analysis of EDM Process Parameters by Using Coated Electrodes, International Journal of Engineering Trends and Technology, vol. 41, no. 4, pp. 181185, 2016, doi: 10.14445/22315381/IJETTV41P234

[11] T. Sathies, V. Krishnaraj, R. Naveen Anthuvan, Enhancement of Material Removal Rate in Micro EDM of Titanium Alloy using Coated Electrodes, Advances in Natural and Applied Sciences, vol. 11, iss. 8, pp. 82-89, 2017.

[12] S.S. Shirguppikar, M.S. Patil, V.S. Ganachari, T.V. Kolekar, P.S. Jadhav, A.B. Chougule, Experimental Investigation of CNT Coated Tools for EDM Processes, Materialstoday: Proceedings, vol. 5, iss. 2, pp. 7131-7140, 2018, doi: 10.1016/j.matpr.2017.11.378

[13] D. Tijo, S. Kumari, M. Masanta, Ceramic-metal Composite Coating on Steel Using a Powder Compact Tool Electrode by the Electro-Discharge Coating Process, Silicon, vol. 10, pp.1625-1637, 2018, doi: 10.1007/s12633-017-9646-6

[14] J. Zhang, Fabrication of TiN-Cu electrical discharge machining electrode by gel injection molding, Chinese Journal of Vacuum Science and Technology, vol. 39, no. 2, pp. 169-173, 2019.

[15] A.A. Khan, Electrode wear and material removal rate during EDM of aluminum and mild steel using copper and brass electrodes, The International Journal of Advanced Manufacturing Technology, vol. 39, no. 5-6, pp. 482-487, 2008, doi: $10.1007 / \mathrm{s} 00170-007-1241-3$

[16] L. Li, Y.S. Wong, J.Y.H. Fuh, L. Lu, Effect of TiC in copper-tungsten electrodes on EDM performance, Journal of Materials Processing Technology, vol. 113 , iss. $1-3$, pp. 563-567, 2001, doi: 10.1016/S0924-0136(01)00622-7

[17] S.S. Shirguppikar, M.S. Patil, M. Ranade, Experimental Investigation of Coated and Uncoated Tools Used in Electro Discharge Machining Process for Machining of TI-6AL-4V, International Journal of Mechanical Engineering and Technology, vol. 10, iss. 8, pp. 150-165, 2019.
[18] S.S. Shirguppikar, M.S. Patil, Experimental Investigation of CNT Coated Tools for EDM Processes, Materialstoday: Proceedings, vol. 5, iss. 2, pp. 7131-7140, 2018, doi: 10.1016/j.matpr.2017.11.378

[19] S. Shirguppikar, M. Patil. Performance Analysis of Multi Wall Carbon Nanotubes (MWCNT) Coated Tool Electrode During Machining of Titanium Alloy (Ti6Al4V), in International Manufacturing Science and Engineering Conference, 3 September, 2020, Virtual, Online, vol. 2, American Society of Mechanical Engineers, pp. 113, 2020, doi: 10.1115/MSEC2020-8224

[20] S.S.Shirguppikar, M.S. Patil. Experimental investigation on micro-electro discharge machining process using tungsten carbide and titanium nitridecoated micro-tool electrode for machining of Ti-6Al$4 \mathrm{~V}$, Advances in Materials and Processing Technologies, Latest Articles, pp. 1-18, 2020, doi: 10.1080/2374068X.2020.1833399

[21] A. Mahajan, G. Singh, S. Devgan, S.S. Sidhu, EDM performance characteristics and electrochemical corrosion analysis of $\mathrm{Co}-\mathrm{Cr}$ alloy and duplex stainless steel: A comparative study, Proceedings of the Institution of Mechanical Engineers, Part E: Journal of Process Mechanical Engineering, Article first published online, 2020, doi: 10.1177/0954408920976739

[22] P.S. Bains, M. Bahraminasab, S.S. Sidhu, G. Singh, On the machinability and properties of Ti-6Al-4V biomaterial with n-HAp powder-mixed ED machining, Proceedings of the Institution of Mechanical Engineers, Part $\mathrm{H}$ : Journal of Engineering in Medicine, vol. 234, iss. 2, pp. 232242, 2020, doi: 10.1177/0954411919891887

[23] G. Singh, T.R. Ablyaz, E.S. Shlykov, K.R. Muratov, A.S. Bhui, S.S. Sidhu, Enhancing corrosion and wear resistance of Ti6Al4V alloy using CNTs mixed electrodischarge process, Micromachines, vol. 11, iss. 9, pp. 1-16, 2020, doi: 10.3390/mi11090850

[24] G. Singh, S.S. Sidhu, P.S. Bains, M. Singh, A.S. Bhui, On surface modification of Ti alloy by electro discharge coating using hydroxyapatite powder mixed dielectric with graphite tool, Journal of Bioand Tribo-Corrosion, vol. 6, iss. 3, pp. 1-11, 2020, doi: 10.1007/s40735-020-00389-0

[25] S.S. Sidhu, A. Batish, S. Kumar, Study of surface properties in particulate-reinforced metal matrix composites (MMCs) using powder-mixed electrical discharge machining (EDM), Materials and Manufacturing Processes, vol. 29, iss. 1, pp. 4652, 2014, doi: 10.1080/10426914.2013.852211

[26] M. Bhaumik, K. Maity, Effect of different tool materials during EDM performance of titanium grade 6 alloy, Engineering Science and Technology, 
an International Journal, vol. 21, iss. 3, pp. 507-516, 2018, doi: 10.1016/j.jestch.2018.04.018

[27] N. Ekmekci, B. Ekmekci, Electrical discharge machining of Ti-6Al-4V in hydroxyapatite powder mixed dielectric liquid, Materials and Manufacturing Processes, vol. 31, iss. 13, pp. 1663-1670, 2016, doi: $10.1080 / 10426914.2015 .1090591$

[28] L. Zhao, Z. Li, L. Feng, X. Bai L. Li, Surface characteristics of Ti-6Al-4V by sic abrasive-mixed EDM with magnetic stirring, Materials and Manufacturing Processes, vol. 32, iss. 1, pp. 83-86, 2017, doi: 10.1080/10426914.2016.1151043

[29] M. Kolli, A. Kumar, Effect of dielectric fluid with surfactant and graphite powder on electrical discharge machining of titanium alloy using taguchi method, Engineering Science and Technology, an International Journal, vol. 18, iss. 4, pp. 524-530, 2015, doi: 10.1016/j.jestch.2015.03.009

[30] N. HuuPhan, T. Muthuramalingam, N.N. Vu, N.Q. Tuan, Influence of micro size titanium powders mixed dielectric medium on surface quality measures in EDM process, International Journal of Advanced Manufacturing Technology, vol. 109, pp. 797-807, 2020, doi: 10.1007/s00170-02005698-9

[31] T. Muthuramalingam, B. Mohan, S. Vignesh, Performance Analysis of Pulse Generators on Residual Stress of Machined Silicon Steel Using EDM Process, Silicon, vol. 10, iss. 5, pp. 17851792, 2018, doi: 10.1007/s12633-019-00287-2
[32] T. Muthuramalingam, B. Mohan, A. Jothilingam, Effect of tool electrode re-solidification on surface hardness in electrical discharge machining, Materials and Manufacturing Processes, vol. 29, iss. 11-12, pp. 1374-1380, 2014, doi: $10.1080 / 10426914.2014 .930956$

[33] R.K. Roy, A primer on the taguchi method, Society of Manufacturing Engineers, 1990.

[34] M.N. Islam, A. Pramanik, Comparison of Design of Experiments via Traditional and Taguchi Method, Journal of Advanced Manufacturing Systems, vol. 15, no. 3, pp. 151-160, 2016, doi: $10.1142 /$ S0219686716500116

[35] A. Rafidah, A. Nurulhuda, A. Azrina, Y. Suhaila, I.S Anwar, R.A. Syafiq, Comparison Design of Experiment (DOE): Taguchi Method and Full Factorial Design in Surface Roughness, Applied Mechanics and Materials, vol. 660, pp. 275-279, 2014, doi: 10.4028/www.scientific.net/AMM.660.275

[36] A.J. Thomas, J. Antony, A comparative analysis of the Taguchi and Shainin DoE techniques in an aerospace environment, International journal of productivity and performance management, vol. 54, iss. 8, pp. 658-678, 2005, doi: $10.1108 / 17410400510627516$

[37] B. Aksu, Baynal, K., Shainin and Taguchi Methods and their comparison on an application, in $1^{\text {st }}$ International symposium on Computing in Science and Engineering, 3-5 june, 2010, Izmir, Kusadasi, Turkey, pp. 1-9. 